\title{
Nutritional Assessment of Cardio-thoracic Critically III Patients:Review of Literature
}

\author{
El-mattryES1 ‘Khalil NS2 ،Ismail MS3 and Reshia FA2 \\ 1Registered nurse at Damietta Chest Hospital \\ 2Department of Critical Care and Emergency Nursing, Faculty of Nursing, Cairo \\ University, Egypt \\ 3Department of Critical Care and Emergency Nursing, Faculty of Nursing, Cairo \\ University, Egypt \\ 4Department of Nursing, College of Applied Medical Sciences, Jouf University, Sakākā,

\section{KSA.} \\ Critical Care and Emergency Nursing, Faculty of Nursing, Mansoura University, \\ Mansoura, Egypt. \\ *Corresponding author: Enassalahelmattry, Registered nurse at Damietta Chest Hospital, \\ Damietta,Egypt, Tel: 1027000288; Email: enaselmattry8@gmail.com
}

\begin{abstract}
The current literature covered the following section; nutrition for critically ill patients, nutrition for cardiac critically ill patients, nutrition for thoracic critically ill patients, method of nutrition for critically ill patients, malnutrition for cardiac critically ill patients and thoracic critically ill patients, role of critical care nurse in nutritional assessment and management of cardiac critically ill patients and thoracic critically ill patients. Nutrition in critically ill patients; critically ill patients are unable to maintain adequate nutritional intake to meet metabolic demands which neededusually. The critically ill patients are already in a catabolic crisis; therefore expect early feeding to be beneficial. In intensive care units critically ill patients'nutrition becomes internationally a standard of care (Cox \& Rasmussen, 2014).
\end{abstract}


Introduction
Most likely the nutrition positively affects the patient outcomes, it is identified a marker of quality care in ICU settings and is relatively cheap compared to other commonly used treatments (Ridley, Gantner\& Pellegrino, 2015). Early initiation of nutritional support in critically ill patients are in the same way of improved clinical outcomes, lower infection rates, and reduced hospital length of stay (Barr, Hecht, Flavin, Khorana, \& Gould, 2014). Cardiac critically ill patients Nutrition; cardiac critically ill patients need in diet low carbohydrate, low salt and low in saturated fats in diet, with fresh fruit and vegetables, Fatlevel has a strong relation with the risk of coronary artery disease, heart attack and coronary death.Omega- 6 and Omega-3 wasbeing the essential fatty acids for cardiac patients, whichin oily fish and in nuts and seeds (Bochud, Marques-Vidal, Burnier\&Paccaud, 2012). However it is necessary to know that if the total fat intake is greater than $37 \%$ of the total calories that increase the risk of cardiovascular disease. Saturated fat intake should not exceed $10 \%$ of total energy and for high-risk patients, as patients with diabetes; total fat intake should be $7 \%$ or less of total energy (Keene, Price, Shun-Shin \& Francis, 2014).

One of the risk factor for cardiovascular disease was being High blood pressure (hypertension) (Borghi, Urso, \& Cicero, 2017). Hypertensionhas been estimated that a universal reduction in intake of sodium by about 1 gram (gm) of sodium a day, about $3 \mathrm{gm}$ of salt, would lead to a $50 \%$ reduction in the number of patient who need treatment for hypertension (Eilat-Adar, Sinai, Yosefy, \&Henkin, Y. 2013). Eating a diet high contains a lot of vitamins and minerals like fresh fruits and vegetablesto protect the heart disease and stroke (Gutierrez, Ramirez, Rundek\&Sacco, 2012). Thoracic critically ill patients Nutrition;nutrition is a significant issue in managing patients with chest diseases, because these patients are at increased risk of malnutrition as the disease progresses.Overweight patients needlungsand heart work harder and their breathing become more difficult. In addition, might need more oxygen. In contrast, being underweight make patient feel tiredand weak, and might make him more risk to get an infection. (Baldi, Aquilani, Pinna, Poggi, Martini \&Bruschi, 2010).

Thoracic critically ill patients need protein for more energy intensity and need carbohydrates: 4 kcal $(17 \mathrm{~kJ})$ per gram; in contrast, lipids supply $9 \mathrm{kcal}$ (37 kJ) per gram: 4 kcal $(17 \mathrm{~kJ})$ per gram; in contrast, lipids supply $9 \mathrm{kcal}$ $(37 \mathrm{~kJ})$ per gram. Amino acid is the most important defining and part of characteristic of protein, which from a nutritional stand point (Phillips, Stuart, Loon, Luc \& Van, 2011). Protein produces antibodies to fight infection. Loss of protein and not ability to keep a good nutritional status may severely decrease the lungs ability to defend against infection, in respiratory disease patients. Protein is helpful if patients have an infection and they need more of protein (Wetering, Hoogendoorn, Broekhuizen, Geraerts-Keeris, Munck\&Molken, 2010). The Priority Research Centre for Healthy Lungs focuses on eating more fruit and vegetables is a simple, it is very effective strategy for getting healthier, rich in vitamins, fibre and minerals, has shown beneficial for the lungs, eat about seven 
servings per day. Fruit and vegetables are helpful for controlling weight (Wood, 2012).

Methods of nutrition forcritically ill patients; nutrition should be administered through two ways to patients in ICU, Enteral Nutrition (EN) and $(\mathrm{PN})$. Enteral nutrition is the method of feeding which used tubes through the gastrointestinal Tract (GIT) for delivering nutrition that give patients part or all of their caloric requirements. EN participates in the management of patients which have a poor voluntary oral intake chronic neurological or intestinal failure or mechanical dysphagia and in the critically ill patient (Blumenstein, Shastri\& Stein, 2014). Enteral Nutrition is not more physiological than Parenteral Nutrition, but has also been to improve patient's outcomes, reduce costs and decrease septic complications in comparison to PN. Early enternal nutrition (within one day to two days) after admission into ICU was associated with reduce mortality (Blumenstein, Shastri\& Stein, 2014).

Entral nutrition divided to two ways: oral and tube. Oral is the normal way to feeding. Tubes insert by some ways: from the nose to the stomach, which is the most common way, duodenum, which is the first part of small intestine or the jejunum, which is the second part of small intestine, jejunostomy and gastrostomy tubes which inserted during skin (percutaneous) through a small incision on the upper abdominal wall, which was done by a Radiologist with X-ray guidance, by an Endoscopist via endoscopy, or by surgically. Short-term enteral nutrition is known as used less than 4 weeks usually but long-term enteral nutrition is used for more than 4 weeks (Freeman, Ricevuto\&DeLegge,
2010). Enteral nutrition is a reason of some complications like: food entering on patient lungs (aspiration), constipation, incorrect reduction of nutrients, nausea, vomiting, diarrhea, dehydration, abnormalities in electrolyte, hyperglycemia, vitamins and minerals deficiencies, and reduce liver proteins. Enteral feeding tubes inserted through the nose as nasogastric tube, which cause irritate in nose or throat, make ulcer in the larynx or esophagus, and acute sinus infections. Enteral feeding tubes inserted during skin of the abdominal wall, as jejunostomy or gastrostomy tubes, may become displaced or clogged, and occur wound infections sometimes (Ramprasad, \& Kapoor, 2011).

Parenteral nutrition refers to delivery of nutrients and calories through veins. This is like a carbohydrate calories delivered as a sugar through intravenous solution or all of the needed nutrients which delivered including carbohydrate, fat, protein, vitamins, electrolytes (as sodium and potassium), and trace elements (as copper and zinc) (Racco, 2012). Parenteral nutrition access options include Central Venous Catheter (CVC) and Peripherally Inserted Central Catheter (PICC). CVC includes short term catheter that insert in the hospital and removed prior to discharge and long term options as tunneled Hickman catheters which inserted in the upper chest. CVC is used for patient requiring weeks or months of therapy (Nordquist, 2016). PICC inserted in the upper arm. PICC is available to let infusion of different fluids or medications. PN and EN can improve nutrient delivery to critically ill patients. When EN alone is inadequate, some experts are device to use of PN and EN together to meet energy and protein targets. Parenteral nutrition is given only when $\mathrm{EN}$ is 
contraindicated (short gut syndromes, proximal high output fistula, perforated bowel, bowel obstruction, severe gastrointestinal bleed, and severe hemodynamic instability (Khalid, Doshi\&DiGiovine, 2011).

PN used to keep hydrated and to extend calories and nutrients to patient that allow development and growth of physical well-being and function. Because of, nutritional requirements and patient's calorie not met by the current level of functioning of their GIT (Calder, Jensen, Koletzko, Singer \&Wanten, 2010). There are many reasons for $\mathrm{EN}$ and PN involving GIT problems as: short bowel syndrome, bowel obstruction, Crohn's disease, and ulcerative colitis; as well as GIT cancer or comatose patients. Some patients have a variety of medical issues that produce the safe use of the GIT difficult, when EN is choose technically possible (Elia, Russell, Stratton, Todorovic, Evans \&Farrer, 2011). Critically ill patients are exposed to many nutritional problems: hypermetabolism nutritional depletion which decrease of muscle and subcutaneous tissue and weight loss, changes in skin, changes in nails, immune dysfunction, gastrointestinal dysfunction, gastrointestinal bleeding, and malnutrition (Cuesta \& Singer, 2012)

Hypermetabolic response is a part of the adaptive response to critical illness. Several mechanisms in stress which have been maintained through evolution are triggered to excess the provision of energy substrates to vital tissues, help pituitary hormones to release, stimulation of the sympathetic and peripheral nervous system resistance the effect of anabolic factors (Cuesta, Singer, 2012). The researchers submit that hormonesmay be involved as additional triggers of the response to stress and critical illness which released from the gut and adipose tissue. Clinically, there are appeared as a variety of changes which include excess of energy expenditure, loss of muscle mass, stress hyperglycemia, and eventually psychological and behavioral problems (Cuesta, Singer, 2012). The most skin changes reported as (pigmentation, lesions, edema, abnormal coloring, presence of pressure sores and turgor). Pressure sores are the biggest problem in the skin as a result of nutritional problems. Pressure sores occur when the skin and tissues are squeezed by bone against an outside surface, on weightbearing parts of body where the skin is near the bones. Bedsores develop with malnutrition and bedridden patients usually (Piton, Manzon\&Cypriant, 2011).

Common sites of pressure sores are shoulder blades, hips, elbows, base of the spine, knees, heels, ankles and even between fingers and toes. Pressure sores have four stages: Stagelthis is the first stage. Pressure sores only effect on the upper layer of the skin. Stage2 this is the second stage which happens when the sore digs deeper below the surface of skin. Stage 3 this is the third stage which sores have gone through the second layer of skin into the fat tissue. Stage4 these sores are the most serious. Some may even effect on ligaments and muscles and arrive to bone (Piton, Manzon\&Cypriant, 2011). The common problems in the critically ill patient are gastrointestinal dysfunction. Gastric emptying delayed impaired intestinal barrier integrity and abnormal motility patterns are observed in patients who admitted in the Intensive Care Unit (ICU). An important sign in clinical outcome of patients in the ICU is a 
Nutritional Assessment of Cardio etc...

functional gastrointestinal tract (GIT). The development of symptoms revealing of gut dysfunction is related with enteral feeding failure, complications and morbidities, thatmay all affect survival. A functional gut is considered have importance and clinical relevance in the critically ill patient (Hill, Miller \&Michell, 2011).

Disorders of gastrointestinal motilityare interpretedas vomiting, gastric retention, absent/abnormal bowel sounds, distension, diarrhea and ileus. In the fact, motility during the GIT is abnormal through severe illness; gastrooesophageal sphincter tone is extremely poor and gastro-oesophageal reflux frequently combined with bad oesophageal peristaltic clearing of refluxed contents occurs (Poulard, Dimet\& Martin-Lefevre, 2010). Gastrointestinal bleeding, it has some signs as haematemesis, blood-stained nasogastric drainage, coffee grounds vomitus, melena stool and importance clinically signs as drops in haemoglobin or blood pressure reportedly occur with varying severity in up to half of all ICU patients, bleeding in the intestinal tract in critically ill patients is indicative of mucosal stress injury (Morrow, Kollef\&Casale, 2011). In fact, in severely stressed patients gastrointestinal bleeding is only one manifestation of loss of mucosal integrity. Villous ischemia-reperfusion damage in haemodynamic instability and hypotension leads to epithelial morphological disruption, have blunted effect on villous height, apoptotic and necrotic cell loss, and shedding of enterocytes into the gut lumen. This equalization of the complex process participated in normal gut barrier function, leading to increase intestinal permeability (Shimizu, Ogura, \&Hamasaki, 2011).

Malnutrition is known as to depict any imbalance in nutrition, as in hospitals and ICU. Malnutrition developed as a result of deficiency in dietary intake, excessed requirements associated with a disease state, from an underlying illness complications such as bad absorption and excessive nutrient losses, or from a combination of these afore mentioned factors. Bad results for patients, including higher infection and complication rates was associated with malnutrition. The costs of treating patients with disease-related malnutrition are more expensive than treating a patient without malnutrition. The costs have been evaluated at $20 \%$ higher than treating a patient without malnutrition (Caccialanza, Klersy\&Cereda, 2010). Malnutrition is a state of nutrition that is insufficiency of energy, protein, and other nutrients which reasons measurable reverse effects on tissue/body form (body shape, size and composition), function, and clinical outcome. In malnutrition happen reducing in body cell mass, organ dysfunction, and abnormal serum chemistry values as a result of an alteration of body composition deficiencies of macronutrients and micronutrients (Elia, Russell, Stratton, Todorovic, Evans \&Farrer, 2011).

Malnutrition occurs when the nutritional intakes does not meet metabolic requirements. Hypermetabolism is the major physiologic change in critical illness. Protein is reduced in anabolic responses secondary to decreased physical activity and the use of neuromuscular blockade agents through mechanical ventilation and protein breakdown is excessed because of infection, operative trauma, cause muscle wasting and commonly 
when using drugs as corticosteroids. Energy deficits can increase complications of infection, use mechanical ventilation for prolonged time, and increase stay in ICU, morbidity, and mortality (White, Guenter\& Jensen, 2012). Critical care nurses should perform nutrition assessment, which is used to record progress of nutritional outcomes for patients in the ICU and early enternal nutrition should be start to critically ill patients with a functioning gut who are not look forward to be taking adequate intake (more than $50 \%$ of needs) in 48 hours, if enteral nutrition is not at $80 \%$ of goal for energy after 48 hours in nutritionally high-risk patient, parenteral nutrition should be start. On the other side, indications of supplemental parenteral nutrition benefit are present for long staying ICU patients and in high mortality risk (Wischmeyer, 2011).

Nutritional support help in limiting the loss of body mass through critical illness, and nutritional risk. The aim of nutritional assessment is identify patients who benefit from nutritional intervention in the ICU. Nutritional support must be a routine part present to critically ill patients in their care. It is now participate in the prevention of malnutrition and specific nutrient deficiencies. It is assumed to improve outcomegenerally. (Henneman, Gawlinski\&Giuliano, 2012). The importance of nutritional support is providing patients with their general nutrient requirements. Nevertheless, medical team should be known that requirements will need to be modified as individual patient needs and specific disease processes. (McClave, Martindale, Rice \&Heyland, 2014).Nutritional support is oftentimes considered in terms of macronutrients and micronutrients. As a first step for nutrition to the patient need, it begins with estimating total fluid requirements.Assessments of the state of nutrition, or more accurately the level of nutritional deficit, of patients are clearly the first step in deciding the degree of nutritional support required (Malone, 2014).

The American Society for Parenteral and Enteral Nutrition (A.S.P.E.N.), expose that patients in hospital should be assessed from admission about risk of malnutrition, by performing of a nutritional assessment for patients who at risk of malnutrition or patients with actual malnutrition(Banks, Bauer \& Graves, 2010).Nutritional assessment is known by the American Society for Parenteral and Enteral Nutrition (ASPEN), using nutritional,medical and medication histories,laboratory data,physical examination andanthropometric measurements to determine the nutritional status of patients(White, Guenter\& Jensen, 2012). The essence of nutritional assessment is to identify nutritional disorders and determine that individuals need nutritional instruction and or nutritional support. Detection of malnutrition can be facilitated by the use of a simple and reliable nutritional assessment (Chan, Lim, Ernest \& Tan, 2010). Nutritional assessment included parts as anthropometrics measurements and biochemical assessment.Biochemical markers which included three parameters as serum albumin, White blood cells (WBCs), also called leukocytes and total cholesterol. Serum albumin that is the most commonly used marker for nutritional state. However, albumin can be affected by not only nutritional state but by other factors, including inflammation and infection (Adegbusi\&Sule, 2011). 
Albumin is a protein synthesis by the liver. Measurement of albumin is in the urine and blood. In the blood, a serum albumin measures the amount of protein in the clear liquid portion. Albumin take part in move many small molecules through the blood, inclusive bilirubin, progesterone, calcium and medicines. The normal range of albumin is $(3.4$ to $5.4 \mathrm{~g} / \mathrm{dL})$. Normal value ranges sometimes have varied slightly among different laboratories. Albumin performs an important role in the movement of the fluid from the blood and leaking out into the tissues. The level of albumin help to detect if patients have liver disease or kidney disease, or if the body does not absorb enough protein (Albert, 2010). Increasing the level of blood albumin is due to: high protein diet, dehydration. Signs of decreasing the level of albumin in blood is: liver disease (for example: cirrhosis or hepatitis) and kidney diseases. When the body does not take or absorb enough nutrients, the level of blood albumin decreased. There is some nutrient disease that decreased level of albumin in body as:Crohn disease, after weight-loss surgery, Low-protein diets, Celiac disease, Whipple disease and with malnutrition. (Richard, Matthew \& Bernard, 2011).

White blood cells (WBCs), also called leucocytes or leukocytes. WBCs are cells of the immune system which participated in the protection of the body against foreign bodies and infectious disease. WBCs are generated from the cells in the bone marrow known as hematopoietic stem cells. Leucocytes are found in blood and lymphatic system (Kenneth, 2012).The count of leukocytes in the blood is often an indicator of some disease. The normal number of WBCs is between $4 \times 109 / \mathrm{L}$ and $11 \times 109 / \mathrm{L}$. In the US count of WBCs are expressed as
4,000 to $11,000 \mathrm{WBCs}$ per microliter of blood. WBCs form around $1 \%$ of the total blood volume in a healthy adult, making them substantially less numerous than the RBCs at $40 \%$ to $45 \%$ (Kumar, Fausto\& Abbas, 2010). However, these WBCs which represent $1 \%$ of the blood makes a large difference to health, because of immunity depend on them. Leukocytosis is defined as excessing in the number of leukocytes over the upper limits. Leukocytosis is normal when it is part of healthy immune responses which happen frequently, and become abnormal, when it is neoplastic or autoimmune in origin. Leukopenia is defined as reducing in the number of leukocytes beneath the lower limit. It shows weakens in the immune system (Kaushanskyetal., 2010).

Cholesterol is a waxy material that is generated by the liver naturally. It protects the nerves, produces hormones and makes cell tissues. Normal range for total cholesterol is (180 to $200 \mathrm{mg} / \mathrm{dL}$ ). One of the controllable risk factors for coronary heart disease, stroke and heart attack was high cholesterol which is the major one. The risk of malnutrition which associated with low serum cholesterol is increased. The main value of biochemical markers is in a detailed assessment and monitoring for the patient status (Fox, Golden \& Anderson, 2015). Anthropometric measurements are quantitative techniques and noninvasive to assess an individual's body fat structure by measuring, analyzing, and recording specific measurements of the body, such as height, weight, skin-fold thickness, and bodily circumference at the waist, chest and hip. There are indicated to comparative measurements of the body (Cavalcanti, Rocha \&Vannier, 2014). Anthropometric measurements are used 
in nutritional assessments. For adult patients medical staffs use anthropometric measurements which include height, weight, body mass index (BMI) and percentage of body fat. These measures are important to determine weight status and the risk for various diseases (Cavalcanti, Rocha \&Vannier, 2014).

Anthropometric measurements demand precise measuring techniques to be valid. Researchers in various health disciplines, which including cardiovascular health, nutrition, gerontology and occupational health to inspect health status and health care utilization trends use anthropometric data. Anthropometric data have many uses as: to evaluate health, dietary status, disease risk, and body composition changes occur over the adult lifespan (Wagner et al., 2011).

\begin{tabular}{|c|c|c|c|}
\hline \multicolumn{4}{|c|}{ Measurements of Anthropometric } \\
\hline Test & Gender & Normal Values & Malnutrition Values \\
\hline \multirow{2}{*}{ Triceps Skinfold (TSF) } & $\sigma^{\pi}$ & $11-12.5 \mathrm{~mm}$ & $7.5-11 \mathrm{~mm}$ \\
\hline & 우 & $15-16.5 \mathrm{~mm}$ & $10-15 \mathrm{~mm}$ \\
\hline \multirow{2}{*}{ Mid Upper Arm Circumference (MUAC) } & $0^{\pi}$ & $26-29 \mathrm{~cm}$ & $20-26 \mathrm{~cm}$ \\
\hline & o & $26-28.5 \mathrm{~cm}$ & $20-26 \mathrm{~cm}$ \\
\hline \multirow{2}{*}{$\begin{array}{l}\text { Arm Muscle Circumference } \\
\text { (AMC) }\end{array}$} & $0^{\pi}$ & $23-25 \mathrm{~cm}$ & $16-23 \mathrm{~cm}$ \\
\hline & 오 & $20-23 \mathrm{~cm}$ & $14-20 \mathrm{~cm}$ \\
\hline
\end{tabular}

Height measured according to equation when patients were bedridden: Male height with centimeters $(\mathrm{cm})=$ $64.19-(0.04 X$ age $)+(2.02 X$ knee Height $\mathrm{cm})$, Female height with $\mathrm{cm}=$ $84.88-(0.24 \mathrm{X}$ age $)+(1.83 \mathrm{X}$ knee Height $\mathrm{cm})$.Weight calculated in kilograms be use a digital weight scale, or measure according to equation when patients were bedridden: Female weight $=(0.98 \mathrm{X}$ Arm Circumferences $(\mathrm{AC})$ in $\mathrm{cm})+(1.27 \mathrm{X}$ Calf Circumferences(CC) in $\mathrm{cm})+(0.4 \mathrm{X}$ Subscapular Skin fold Thickness (SSF) in $\mathrm{cm})+(0.87 \mathrm{X}$ Knee Height $(\mathrm{KH})$ in $\mathrm{cm})-62.35$, Male weight $=(1.73 \mathrm{X}$ Arm Circumferences $(\mathrm{AC})$ in $\mathrm{cm})+(0.98 \mathrm{X}$ Calf Circumferences (CC) in $\mathrm{cm})+(0.37 \mathrm{X}$ Subscapular Skin fold Thickness SSF in $\mathrm{cm})+(1.16 \mathrm{X}$ Knee Height $(\mathrm{KH})$ in $\mathrm{cm})-81.69$, and Body Mass Index (BMI) measured be use this equation $(\mathrm{BMI})=$ weight $(\mathrm{kg}) /$ height $(\mathrm{m})^{2}$ (Rolland, Perrin, Gardette, Filhol, \&Vellas, 2012).

Body Mass Index is used to observe weight categories: underweight (BMI values < 18.5), normal weight (18.5 - 24.9), overweight (25.0 - 29.9), obesity - Class I (30.0 - 34.9), obesity Class II (35.0 - 39.9) and extreme obesity (BMI values $>40.0)$. The measurement of Arm Circumferences is taken at the level of the upper arm mid-point mark on the right arm. The measurement in millimeters of Skinfolds is using the Holtain skinfold caliper. The subscapular skinfold are measured at the inferior angle of the right scapula (Bell, Bruce, Tamura, Masaki \&Amella, 2013). The role of Critical Care Nurses (CCNs) included checking patients' vital signs, assisting physicians during procedures, taking blood samples and managing ventilation of critically ill patients. CCNs also administer medication and provide patients with personal care, such as dressing and bathing. CCNs support and educated both the patient and the patient's family. CCNs liaise with the new team to ensure a safe transition, when a patient is discharged from the ICU and transferred to another unit in the hospital (Dale, Angus, Sinuff\&Mykhalovskiy, 2013). Intensive care units are heavy in technology, and CCNs should control the various pieces 
of equipment when still maintaining human contact with severely ill patients who not are able to communicate (Greenwood, 2010). CCNs collect relevant data for the critically ill patient, identify outcomes, implement the plan, develop a plan that prescribes interventions to attain outcomes coordinate care delivery and employ strategies to promote health and a safe environment and evaluate progress toward attaining outcomes for the patient (Linda, 2010).

Critical Care Nurses have a great impact on patient care. CCNs monitor nutritional status of patients and monitor complications appearance on patients because of they spend a lot of time near patients more than other health care provider (Soroksky, Lorber\&Klinowski, 2010). CCNs are initiation nutrition with patients according medical reports. CCNs delivered enteral feeding and count the amount of enteral nutrition delivered and help in treatment complications associated with enteral feedings. CCNs need to ensure the time to continue enternal nutrition when interruptions are no longer necessary (Poulard, Dimet\& Martin-Lefevre, 2010). Critical Care Nurses should eliminate and decrease the time passes without enternal feeding after consultation with the team of medical staff. It is important to confirm of timing for procedures that require the interruption of enteral nutrition to limit the number of hours the patient remains unable to feeding because it is allow the patients to start enteral nutrition as long as possible. (Montejo, Minambres\&Bordeje, 2010). Critical Care Nurses caring for critical care patients should carry out regular nutrition assessment. Chest diseases patients should take a special diet. Breathing for patients with respiratory disease requires more energy. The muscles of chest diseases patients need 10 times more calories than those of a patient without respiratory disease in breathing. Ideal nutrition supports the body against infections. Patients with respiratory diseaseare more expose to chest infections lead to hospitalization. It is important to decrease risk ofexpose to infection for patients with respiratory diseaseby following a healthy diet (Evans, 2011).

References:

Adegbusi, H. S. \&Sule, M. S. (2011). Anthropometric and Biochemical Assessment Among Under Five Children in Kusada Local Government Area, Katsina State, Nigeria. Bayero Journal of Pure and Applied Sciences, 4(2), 137140

Albert, F. (2010). Albumin Usage in Clinical Medicine: Tradition or Therapeutic? Transfusion Medicine Reviews, 24 (1): 53-63.

Baldi, S., Aquilani, R., Pinna, G. D., Poggi, P., Martini, A. \&Bruschi, C. (2010). Fat-free mass change after nutritional rehabilitation in weight losing COPD: role of insulin, Creactive protein and tissue hypoxia. International Journal of Chronic obstructive Pulmonary Disease, 5(2), 29-39.

Banks, M., Bauer, J. \& Graves N. (2010). Malnutrition and pressure ulcer risk in adults in Australian health care facilities.Nutrition Journal, 26(9), 896-901.

Barr, J., Hecht, M., Flavin, K., Khorana, A. \& Gould, M., K. (2014). Outcomes in Critically Ill Patients before and after the Implementation of an EvidenceBased Nutritional Management 
Protocol.CHEST Journal, 125(4), 1446- 1457.

Bell, C. L., Bruce, K., Tamura, B. K., Masaki, K. H. \&Amella, E. J. (2013). Prevalence and Measures of Nutritional Compromise Among Nursing Home Patients: Weight Loss, Low Body Mass Index, Malnutrition, and Feeding Dependency, A Systematic Review of the Literature. Journal of the American Medical Directors Association, 14(2), 94-100.

Blumenstein, I., Shastri, M. Y. \& Stein, J. (2014). Gastroenteric tube feeding: Techniques, problems and solutions. World $J$ Gastroenterol, 20(26), 85058524.

Bochud, M., Marques-Vidal, P., Burnier, M. \&Paccaud, F. (2012). Dietary Salt Intake and Cardiovascular Disease: Summarizing the Evidence. Public Health Reviews, 33(2), 530-552.

Borghi, C., Urso, R. \& Cicero, A. F. (2017). Renine-angiotensin system at the crossroad of hypertension and

hypercholesterolemia.Nutrition,

Metabolism \& Cardiovascular Diseases Journal, 27 (3): 115120.

Caccialanza, R., Klersy, C. \&Cereda, E. (2010). Nutritional parameters associated with prolonged hospital stay among ambulatory adult patients. CMAJ, 182(17), 1843-1849.

Calder, P. C., Jensen, G. L., Koletzko, B. V., Singer, P., \&Wanten, G. J. (2010). Lipid emulsions in parenteral nutrition of intensive care patients: current thinking and future directions.
Intensive Care Med, 36(6), 735749.

Cavalcanti, M. G., Rocha, S. S. \&Vannier, M. W. (2014). Craniofacial measurements based on 3D-CT volume rendering: implications for clinical applications. Journal of Head and Neck Image, 33(3), 20-45.

Chan, M., Lim, Y.P., Ernest, A. \&Tan,T.L. (2010). Nutritional Assessment in An Asian Nursing Home and Its Association with Mortality. The Journal of Nutrition, Health \& Aging, 14(1), 24-28.

Cox, J. \& Rasmussen, L. (2014). Enteral Nutrition in the Prevention and Treatment of Pressure Ulcers in Adult Critical Care Patients.Critical Care Nurse Journal, 34(6), 15-27.

Cuesta, J.M. \& Singer, M. (2012). The stress response and critical illness: a review. Crit Care Med., 40(12), 3283-3289.

Dale, C., Angus, J.E., Sinuff, T. \&Mykhalovskiy, E. (2013). Mouth care for orally intubated patients: a critical ethnographic review of the nursing literature. Intensive Crit Care Nurs. 29(5), 266-274.

Elia, M., Russell, C., Stratton, R., Todorovic, V., Evans, E. \&Farrer, K. (2011). Members of the Malnutrition Action Group (MAG), a StandingCommittee of the British Association for Parenteral and Enteral Nutrition (BAPEN). A Guide to theMalnutrition Universal Screening Tool (MUST( for Adults. available at www.bapen.org.uk. 
Nutritional Assessment of Cardio etc...

Evans, A. (2011). Nutrition screening in patients with COPD.Nursing Times Journal, 108(11), 12-14.

Fox, C. S., Golden, S. H., Anderson, C. (2015). Update on prevention of cardiovascular disease in adults with type 2 diabetes mellitus in light of recent evidence: A Scientific Statement from the American Heart Association and the American Diabetes Association. Circulation. 132(8), 691-718.

Freeman, C., Ricevuto, A. \&DeLegge, M.H. (2010). Enteral nutrition in patient with dementia and

stroke.CurrOpinGastroenterol, 26(6), 156-159.

Greenwood, B. (2010). Role of Critical Care Nursing.avilable at http./www.Coron.com.

Gutierrez, J., Ramirez, G., Rundek, T. \& Sacco, R. L. (2012). Statin Therapy in the Prevention of Recurrent Cardiovascular Events: A Sex-Based Meta-analysis Statin Therapy to Prevent Recurrent CV Events.Archives of Internal Medicine, 172(12), 909-919.

Henneman, U. A., Gawlinski, A. \&Giuliano, K. K. (2012). Improving Patient Safety in Acute and Critical Care Unit.American Association of Critical-Care Nurses, 32(3), e9-e18.

Hill, L.T., Hill, B., Miller, M. \&Michell, W.L. (2011). The effect of intra-abdominal hypertension on gastrointestinal function.South African Journal of Critical Care, 27(1), 12-19.

Kaushansky, K., Lichtman, M., Beutler, E., Kipps, T., Prchal, J. \&Seligsohn, U., (2010). Williams hematology ( ${ }^{\text {th }}$ ed.). McGraw-Hill, 120-143.

Keene, D., Price, C., Shun-Shin, M. J. \& Francis, D. P. (2014). Effect on cardiovascular risk of high density lipoprotein targeted drug treatments niacin, fibrates, and CETP inhibitors: meta-analysis of randomised controlled trials including 117,411 patients. $B M J$, 349(2), 4379-5472.

Kenneth, S. (2012). Anatomy and Physiology: the Unit of Form and Function ( $6^{\text {th }}$ ed.). McGraw Hill, 230-254.

Khalid, I., Doshi, P. \&DiGiovine, B. (2011). Early Enteral Nutrition and Outcomes of Critically Ill Patients Treated with Vasopressors and Mechanical Ventilation. American Journal of Critical Care, 19(1), 261-268.

Kumar, V., Fausto, N. \& Abbas, A. (2010). Robbins and Cotran pathologic basis of disease. ( $8^{\text {th }}$ ed.). Saunders/Elsevier, 320340.

Linda, B. L. (2010). $A A C N$ Scope and Standards for Acute and Critical Care Nursing Practice (1 ${ }^{\text {st }}$ ed.), AlisoViejo 7-12.

Malone, A. (2014). Clinical guidelines from the American Society for Parenteral and Enteral Nutrition: best practice recommendations for patient care. J InfusNurs., 37(1), 179-184.

McClave, S. A., Martindale, R. G., Rice, T. W. \&Heyland, D.K. (2014). Feeding the Critically Ill Patient.Journal of Critical care medicine, 42(12), 2600-2610.

Montejo, J.C., Minambres, E. \&Bordeje, L. (2010). Gastric residual volume during enteral nutrition in ICU patients: the 
REGANE study. Intensive Care Med., 36(8), 1386-1393.

Morrow, L.E., Kollef, M. H. \&Casale, T.B. (2011). Probiotic prophylaxis of ventilatorassociated pneumonia: A blinded, randomized, controlled trial. $A m J$ RespirCrit Care Med,182(3), 1058-1064.

Nordquist, C. (2016). Nutrition: Why is nutrition important?, available at www.medical news today.com

Phillips, Stuart, M., Loon, Luc, J. C. \& Van, (2011). "Dietary protein for athletes: From requirements to optimum adaptation". Journal of Sports Sciences. 29 (1), S29-S38.

Piton, G., Manzon, C. \&Cypriant, B. (2011). Acute intestinal failure in critically ill patients: Is plasma citrulline the right marker? Intensive Care Med, 37(1), 911917.

Poulard, F., Dimet, J. \& MartinLefevre, L. (2010). Impact of not measuring residual gastric volume in mechanically ventilated patients receiving early enteral feeding: a prospective before-after study. JPEN J Parenter Enteral Nutr., 34(9), 125-130.

Racco, M. (2012). An Enteral Nutrition Protocol to Improve Efficiency in Achieving Nutritional Goals.Critical Care Nurse Journal, 32(4), 72 - 76.

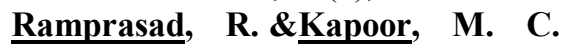
(2011). Nutrition in intensive care.JAnaesthesiolClinPharmacol, 28(1), 1-3.

Richard, A. M. Matthew, R. P. \& Bernard, J. H. (2011). ClinicalDiagnosis and Management by Laboratory Methods $\quad\left(22^{\text {nd }}\right.$ ed. $)$. Elsevier Saunders, 450-470.
Ridley, E., Gantner, D. \&Pellegrino,V. (2015).Nutrition therapy in critically ill patients- a review of current evidence for clinicians.Clinical Nutrition Journal, 4(4), 565-571.

Rolland, Y., Perrin, A., Gardette, V., Filhol, N. \&Vellas, B. (2012). Screening Older People at Risk of Malnutrition or Malnourished Using the Simplified Nutritional Appetite Questionnaire (SNAQ): A Comparison with the MiniNutritional Assessment (MNA) Tool.Journal of Post-Acute and Long-Term Care of Medicine, 13, (1) $31-34$

Shimizu, K., Ogura, H. \&Hamasaki, T. (2011). Altered gut flora are associated with septic complications and death in critically ill patients with systemic inflammatory response syndrome. Dig Dis Sci, 56(2), 1171-1177.

Soroksky, A., Lorber, J. \&Klinowski, E. (2010). A simplified approach to the management of gastric residual volumes in critically ill mechanically ventilated patients: a pilot prospective cohort study. Isr Med Assoc J, 12(2), 543-548.

Wagner, D., Adunka, C., Kniepeiss, D., Jakoby, E., Schaffellner, S., Kandlbauer, M., FahrleitnerPammer, A., ...Tscheliessnigg, K. H. (2011). Serum albumin, subjective global assessment, body mass index and the bioimpedance analysis in the assessment of malnutrition in patients up to 15 years after liver transplantation.ClinTransplant.3( 1) 1-5.

Wetering, C. R., Hoogendoorn, M., Broekhuizen, R., Geraerts- 
Nutritional Assessment of Cardio etc...

Keeris, G. J., Munck, D. R., Molken, R. (2010). Efficacy and costs of nutritional rehabilitation in muscle-wasted patients with chronic obstructive pulmonary disease in a community-based setting: a prespecified subgroup analysis of the INTERCOM trial. Journal of the American Medical Directors Association, 11(3), 179187.

White, J.V., Guenter, P. \& Jensen, G. (2012). Consensus statement: Academy of nutrition and dietetics and American Society for
Parenteral and Enteral Nutrition: Characteristics recommend for the identification and documentation of adult malnutrition (under nutrition). JPEN $J$ Parenter Enteral Nutr, 36(3), 730-739.

Wischmeyer, P. E. (2011). Malnutrition in the acutely ill patient: is it more than just protein and energy? Afr J ClinNutr, 24(3), S1-S7.

Wood, L.G, (2012). Manipulating antioxidant intake in asthma: a randomized controlled trial.Am $J$ ClinNutr, 96(1), 534-543. 